\title{
Donors' Learning Difficulties: Results, Relationships and Responsibilities
}

\section{Rosalind Eyben}

\section{Introduction}

'Power need not learn.'

The UN Millennium Project Report looks at what is wrong with the aid system, including bilateral aid from governments. It notes that such aid is highly unpredictable, poorly targeted, frequently tied, badly coordinated, driven by donor rather than recipient objectives, influenced by the donor's geopolitical interests with resulting policy incoherence and not systematically evaluated (UN 2005). Of this long list, it is with this last point that the present article concerns itself. Why do donor governments have problems with learning and how can they help themselves do better? ${ }^{2}$

Carlsson and Wohlgemuth (2000) present the following reasons why learning is difficult within the aid relationship:

- Political constraints

- The unequal nature of the aid relationship

- Problems internal to the organisation of the aid agency

- The organisations and capacities on the recipient side

- Sources of knowledge and the quality of information.

In the present article, a further reason is proposed, connected to the unequal nature of the aid relationship noted above. I build on an argument made by Curtis (2004), namely the presence of a mindset that seeks control through linear planning, supported by the instruments of performance management.

In exploring the question, I look at the world of aid rather differently than does the Millennium
Project Report. It emphasises the need for more strategies and coherent programming, I respond that this is like recommending brandy as a cure for a hangover. I suggest that donors have overemphasised target orientation to the detriment of relationships and that although working in and contributing to a highly turbulent environment where today's "weak but willing" recipient becomes tomorrow's "corrupt government", donors, as powerful actors have always done, construct a history of that environment that suits them to justify future actions (Nietzsche 1873). They do not learn from history, only abuse it.

As the rationale for aid is to support change for the better, I am interested in why donor governments appear to be ignoring the intellectual developments of the last 20 or so years concerning concepts of change, particularly complexity theory and ideas about improvisation. Is it the absence of an imperative? Organisational and systems learning has developed within the for-profit sector. They have learnt the danger of 'the simplicity trap. By ignoring the contradictions and paradoxes of their environment, businesses are liable to "plot their own demise"' (Clegg et al. 2004: 487). In theory, the public sector equivalent of business' bottom line are citizens to whom governments must learn to respond to stay in power.

Even so, Whitehall, for example, is not very good at learning. The political environment that shapes public sector cultures is averse to experimentation, requires negotiation and compromise between competing power centres in government, suffers from short-termism related to the electoral cycle and maintains traditions of control and secrecy that stifle feedback (Chapman 2002; Common 2004). ${ }^{3}$ Nevertheless, the ballot box does help reality to 
break in. It is absent in the relation between donor governments and the end users of aid.

In what follows, I look at the interplay between accountability, learning and relationships. I suggest that donors might be able to enhance their performance more through improvising rather than through greater efforts at strategic control, and that they can do this responsibly by strengthening their accountability to all stakeholders in the aid system through investing in relationships. I conclude with some practical tips for action that donor organisations could start trying straightaway. As complexity theory tells us, small changes can have big impacts.

\section{Conceptual perspectives}

"Good donorship" has been described as ensuring recipient country leadership, providing support for long-term capacity development, harmonisation and simplification of procedures, transparency and predictability of resources and subsidiarity as a decision-making principle (ODI n.d.). Donors' performance on these matters is currently patchy and the research question as framed by New Institutional Economics (NIE) concerns the incentives that constrain or promote good donorship.

This is a valuable and necessary agenda but one I suggest not sufficient for achieving good donorship. Recipient-donor relations are highly complex with diverse networks of actors that could mutually profit from illumination by a multitude of understandings. To complement the NIE approach offered by such astute analysts as Ostrom et al. (2002), other perspectives can 'thicken' the problem analysis, including a consideration of history, power and the social production and reproduction of meaning (culture) as fundamental to understanding the aid relationship.

In addition to social anthropology and the study of organisations, I suggest complexity theory can help improve the management of the aid relationship. Complexity theory postulates that change is emergent. Organised efforts to direct it more than partially confront the impossibility of our ever understanding the totality of a system that is in constant flux. Composed of innumerable elements, continuously shaped and reformed through interaction upon each other, the system is constantly creating new elements that in turn may affect (loop back) and change those already in existence. Thus, we cannot predict all the effects that any of our actions may have on the wider system, or indeed on ourselves as initiators of the action. Small 'butterfly' actions may have a major impact and apparently significant ones, very little.

The "default" meta-theory of donor governments is one of order, rather than complexity. Based on total certainty, complete rationality, predictability and linked causes and effects, it contrasts with complexity theory that suggests that all of these may possibly be partially but never completely achievable (Geyer 2003). Complexity theory provides a way of thinking about social change and our role in it that embraces rather than ignores or tries to solve paradoxes, of which there are many in the aid relationship. Staying "open to paradox" suggests improvisation as the most effective action. As in jazz, the players have a shared idea of what they might play but through the interaction of the instruments as they perform (and each time it is different) so the score becomes that lived reality rather than that determined in advance (Clegg et al. 2004). The audience judges the performance by what they actually hear. A fundamental ingredient for good jazz is the quality of trust between the members of the band. Whom you play with shapes your product.

Including these other perspectives of course makes life less simple. Recommendations tend to be tentative, less precise, or contradictory. None of these are attractive to a bureaucratic mode of organisation that quintessentially favours clarity, order and predictability - heading straight for the target on the assumption of cause-effect linearity. However, I shall argue that this bureaucratic predilection (which is of course frequently breached in the practice as distinct from the stated policy) is itself a donor weakness when it leads to constructing the world as it would like it to be, risking ignoring how it might appear to others.

Fortunately, the global revolution in communications and the macrosocietal developments associated with it (Castells 1997) is having repercussions in the world of bureaucratic order. Other people's realities are breaking in. Old certainties have disappeared. These changes are affecting how the public sector does its business both at home and abroad. Fresh ideas from a variety of disciplines, including those already cited, are informing organisational learning and understandings of policy processes. ${ }^{4}$ Some of these 
are beginning to influence our thinking about the aid relationship (Carlsson and Wohlgemuth 2000; Biggs and Smith 2003; Pasteur 2004; Groves and Hinton 2004; McGee 2004). Their message is that, while it may be impossible to have a total grasp of the complexity of our global society, each of us has at least some understanding. These varieties of understanding can in dialogue shape responsible policy, one negotiated by respecting difference, where those involved appreciate that there are many ways of understanding the world and its problems. This approach carries implications for accountability within the aid relationship that I shall now explore.

\section{Accountability between governments}

The aid relationship is characterised by a concept of contract, particularly as understood from the donor side, by entitlement, particularly as understood from the recipient side, and by gift exchange, as perceived by both parties (Eyben with León, forthcoming). This mix of characteristics and different points of view concerning the content and purpose of the relationship is likely to lead to less than full agreement concerning either the normative (values and beliefs) or the procedural aspects of accountability arrangements. In the culturally and politically diverse world of the aid relationship, stakeholders may have very different moral perspectives on what it means to be accountable and what makes a quality relationship (Bagic 2004). Even within a single organisation, differences in power relations and values may impede communication and unity of purpose. Apparent agreements may be a reflection of processes that have been described as "colonisation" and "decoupling", to which I return later.

At the Monterrey conference on Financing for Development the "international community" concluded there were the makings of a new development partnership based on a framework of mutual accountability between developed and developing countries (IMF 2002). Sanctions are imposed if accounts are not rendered in contractual and entitlement relationships. The lack of such sanctions leads some to argue (e.g. a number of staff interviewed in SIDA) that "accountability" is a misnomer as applied to aid relations, making a mockery of responsibility if irresponsibility goes unpunished. At Monterrey, recipients pledged to practise good government and donors to provide sufficient resources. There was an understanding on the donor side that they would cut aid if the recipient did not meet its side of the bargain, but the Department for International Development's (DFID's) Fragile States Policy Paper (2005) discusses the problems if such a sanction were applied - those most needing aid would no longer receive it. In my conclusion, I point to this paper's recommendations as a good example of an improvised solution to a paradox that has been recognised rather than ignored.

The incapacity of recipients to apply sanctions on donors should the latter break the Monterrey agreement, confirms that the primary relationship is that of a gift governed by morality and solidarity but not by law. ${ }^{5}$ That donors cannot be forced to behave responsibly may be one of the attractions in providing aid. Foreign interventions in poor countries can buttress a government's prestige and political legitimacy back home without having to be accountable for its actions to those on whom it is having an impact, as it would have to be when operating in the domestic arena (Chandler 2003). This brings us to broader issues of donor accountability, namely to the citizens at either end of the aid chain.

\section{Accountability to citizens: is results-based management the answer?}

Compared with domestic line departments, such as health or education, foreign aid agencies are unusual in the sense that their intended beneficiaries are neither citizens nor residents whose status in theory would give them an "organic" stake in the performance of government agencies and officials. On the contrary, they are very much outside of the public revenue streams on which claims for accountability and entitlement are commonly based. (Johnson 2005).

Donors have been trying to square this circle through the introduction of Results-based Management (RBM) in aid-recipient countries. Governments at Monterrey agreed that improved development effectiveness meant focusing on results and a systematic approach to the monitoring of the actions of all parties (IMF 2002). Although largely driven by donor governments' perceived accountability requirements to taxpayers at home ${ }^{6}$ (Saltmarshe et al. 2003), RBM has the apparently positive effect of donors requiring that as a quid pro 
quo for receiving aid, recipient governments introduce a similar system in their own country. The performance information thus acquired serves the needs of both governments in responding to citizens' demands that the public sector deliver value for money against stated objectives. Thus, donors and recipients can learn together about what works and what does not work in terms of effective aid.

A World Bank document concludes that an RBM approach, based on setting a strategy and then devolving responsibility for implementation, is effective when combined with the devolved organisation's reporting on its performance against the strategy. It enhances accountability to taxpayers and provides the information required for evidencebased policy. The debate is ongoing about the degree to which RBM leads to better organisational performance and/or improved accountability (Roche and Kelly 2003). I suggest, however, that RBM may be symptomatic of donors' current learning difficulties because it ignores the unequal relations of power in fixing the strategy and, as I now discuss, sees all problems as similar.

Underlying RBM is a series of assumptions about the nature of problems.

- There is broad agreement between all parties concerned on the nature of the problem that the strategy has been designed to address.

- There is some mutual understanding of what a solution would look like.

- The problem is bounded in terms of the time and resources required for its resolution (Chapman 2002).

Accountability mechanisms based on the citizens' right to know whether their money has delivered what was promised works well when problems appear to be of this kind. For example, the Mazdoor Kisan Shakti Sangathan (MKSS) movement in Rajasthan demands that public officials provide information about infrastructure projects, such as schools and wells (Johnson 2005). While the failure to deliver a school building may not solve the problem of girls' illiteracy, we can assume that its construction will not make the problem worse.

The current model of public policy making is based on the reduction of problems into separate, rationally manageable components. It works when everyone agrees that these are the required elements for solving a problem but often such an agreement is absent. While in such circumstances a government may seek to impose its understanding of the problem through performance management systems, the outcome can be disappointing. This is the case when problems are "unbounded" or "divergent".

- There is no clear agreement about exactly what the problem is.

- There is uncertainty and ambiguity as to how improvements might be made.

- The problem has no limits in terms of the time and resources it could absorb (Chapman 2002).

Many of the problems governments must cope with (and eliminating global poverty would seem to fit here) are of the unbounded kind. They therefore require a different approach to planning and implementing solutions that recognises rather than ignores the disagreement and uncertainty.

If stakeholders do not have a common view as to what should be the solution then how and to whom should a government be accountable for solving it? I mentioned earlier the idea of improvisation - shared learning through action. This recognises that there are different perspectives about the problem and what counts as success, unlike RBM that determines in advance, both the expected result and the kind of evidence accepted as valid to determine whether that result was achieved.

RBM is usually attributed to taxpayers growing increasingly suspicious of their politicians and civil servants, wanting to know in advance how their money will be spent and checking afterwards it has been spent that way (Meier 2003; Pentland 2000). It may also be a response to the "risk society". Operating in a world of paradox and surprise, there is growing pressure on the public sector to demonstrate its infallibility through logic, control and the use of "objective" evidence for decision making (Beck 1992). The resulting "audit cultures" (Strathern 2000) have been extensively discussed in Britain and are the subject of a current Economic and Social Research Council (ESRC) seminar series. In relation to learning, such cultures require an agreement between those in the accountability relationship about what is acceptable as evidence. To deliver that evidence, organisations may have to change the way they work and the values they adhere 
to (Pentland 2000; Power 1996). Thus, RBM can have a controlling effect. As I now discuss it can also create unintended consequences of resistance.

\section{RBM: the consequences for learning}

A public administration is often a monopsonistic supplier of funds. It has the upper hand in defining what is acceptable knowledge. It not only reshapes the recipient's organisation so that it is capable of delivering the required information but influences how the recipient describes (gives an account of) itself (Strathern 2000). Such a process has been described "colonisation" (Pentland 2000; Power 1996) - a rather sensitive word to use in the context of the aid relationship.

An alternative effect to "colonisation" is "decoupling". This is when an organisation goes through the ritual of imposed procedures but has not internalised their logic or the values underlying them. In this case, the more emphasis on measuring performance, the greater the likelihood the organisation becomes deviant and secretive (Pentland 2000, citing Power 1996). In the new aid relationship, with its aspirations for mutual accountability, the effects of colonisation and decoupling undoubtedly manifest themselves paradoxically and simultaneously, as I experienced every day when in Bolivia (Eyben 2003; Eyben with León, forthcoming).

Among recipients, "colonisation" may offer the possibility of transformative learning - seeing the world in a new way. On the other hand, it can encourage what has been termed "regressive" learning, one of compliance (Vince 2001) or, conversely what could be termed "resistance learning" or the "weapons of the weak" in the sense of power of the donors generating its own resistance.

Most organisations in the aid chain are of course both recipients and donors of funds. I imagine that these different kinds of learning - transformative, regressive and resistance - can occur at the individual, organisational and trans-organisational level in all parts of the aid chain where money flows from the Ministry of Finance down to local government or community-based organisations in the recipient country.

When regressive or resistance learning occurs among the recipients, the donor is discouraged from transformative or "double loop learning" - that is, learning that leads to fundamentally new ways of looking at the issue in question (Pasteur 2004). This is because it reinforces donor claims that they know what the problem is and have the solution to it. Thus, they make only single-loop adjustments to their practice. ${ }^{8}$ They are only learning in relation to how they have previously defined the problem rather than being open to learning through acting in a state of admitted ignorance (Lindblom 1990).

One paradox in the aid relationship concerns the good donorship commitment to donor alignment and harmonisation that can both empower recipient governments through the reduction of their transaction costs, and disempower them through donors ganging up together. ${ }^{9}$ Monterrey's endorsement of results-based management could reinforce the disempowerment pole of the paradox by donors establishing what knowledge is acceptable for defining the problem and identifying the solution. Should this occur, recipient governments would lose their place "in the driving seat". The imperative for upward reporting to donors who have used their power to define the problem and the solution may reduce recipient governments' accountability to their own citizens with potentially different views on the issue. ${ }^{10}$

The same effect may manifest itself in projects. In an exercise on mapping lines of accountability in a Swiss-funded project, workshop participants discovered that although the project's aim had been to strengthen accountability between local actors, the strongest accountability link was to the donor government. In such circumstances, staff time that could have been devoted to strengthening responsible horizontal relationships is diverted to reporting to the donor, the only actor in the project's network of relationships that can apply sanctions if the accountability obligation is not met. ${ }^{11}$

Finally, of course, donors have sought to strengthen recipient governments' downward accountability through developing civil society capacity, often via the provision of funds to international non-governmental organisations (NGOs) to avoid upsetting the government-togovernment relationship. This creates a complex nest of accountability paradoxes for which space constraints prevent further discussion. ${ }^{12}$

In conclusion, I suggest that RBM may have paradoxical effects. First, it can distort or weaken recipients' accountability to their own citizens or intended end-users because of its underlying assumption that all problems are bounded. Second, 
it may constrain transformative learning, the kind of learning required for managing non-bounded problems.

\section{What about the citizens back home?}

A government may not be very accountable for its aid to its citizens back home either, despite the use of RBM. In contrast to their own health or education services, these citizens have no direct contact with the world of aid. They must believe what they are told by those with an interest in the matter government and non-governmental aid agencies. The latter may represent a disinterested constituency, but the donor government's power as a major supplier of funds may limit enthusiasm to criticise government's performance and thus help them learn.

The Millennium Project report notes that a perception of aid being of low quality discourages citizens from supporting increases in the aid budget (UN 2005). The proposed response to such perceptions is to demonstrate what money can deliver in terms of tangible results: so many bed nets or other "quick wins". The public receives a simplified and, I believe, unhelpful impression of how aid works.

The reality is that these results are an effect of aid employees (national and international) building relationships and learning to work on the basis of mutual respect with the governments and communities receiving aid. Their role is rarely emphasised through fear that taxpayers or voluntary donors would interpret this as a "transaction cost" or "administrative overhead", rather than as people making a difference. DFID has recently reduced country office personnel for this reason, because the Treasury does not perceive them as "frontline workers". How can they move from this dilemma towards mutual learning, gaining citizens' support, not by claiming they know what to do but by admitting that when aid works, it is probably due to improvisation by people on the spot?

The complex and contingent nature of social change - and the impossibility of predicting with certainty that a particular event will lead to a certain outcome - suggests a possible donor approach: developing long-term and consistent relations with recipient organisations, including governments, which are pursuing a social change agenda that is compatible with the donor's own values and mission. Rather than aiming to achieve a predetermined, specific real-world change in which the recipient organisation is treated as an instrument to that change, the focus of donor effort would be to support that organisation's own efforts in a turbulent policy environment. ${ }^{13}$

Such a transformation means asking citizens in donor countries to consider the world in a new light. Those at home campaigning for more aid money or more debt relief would need to switch their slogans to investing in relationships rather than in school buildings. This may encourage wider citizen interest if governments can demonstrate that learning through relationships makes taxpayers' money work more effectively for their fellow global citizens at the other end of the aid chain.

\section{Conclusion}

I have argued that when an organisation uses its power to avoid accountability to its end-users, it has no interest in double-loop learning. Such an organisation, interested in history only insofar as it confirms it in its own predilections, will be both ignorant and forgetful. Its power to practise "historical amnesia" (Foucault 1980) will deafen it to the voices and views of others. Instead of inviting their assistance in a mutual construction of the past on which to build a joint future, it ignores their understanding of the world and through this exercise of control may incite resistance not cooperation. I have proposed an alternative that values differences whereby donors will be better able to respond to the complex environment in which aid operates and to which it contributes.

This means a change of mindset. In some circumstances, a focus on concrete results can deliver enhanced performance through strengthened accountability to the end-users. However, used indiscriminately for all and every kind of situation, it distorts relationships, renders invisible much that is needed to be understood, reduces responsibility and blocks the capacity to learn in an unpredictable world. The current enthusiasm for RBM, with its central role for causality (Meier 2003), ignores other ways of understanding the world and weakens aid effectiveness.

There would be more possibility of constructive donor impact if the single-minded concern for results were reduced and greater effort were put into the choice and quality of the relationships on which donors are (paradoxically) dependent for their money and advice to make a difference. They 
would negotiate accountability in terms of mutual responsibility, recognising and working through the paradoxes implicit in the gift relationship and the injustices of history. Finally, they would accept the psychotherapeutic lesson that you cannot change others, only yourself.

Donors are already learning some of this. DFID's recent policy paper on fragile states (2005) demonstrates an awareness of the futility of rushing straight up the hill. It emphasises modest, step-bystep actions which fit well with a recognition of the uncertain and contingent environment of international aid. The same paper recognises that aid has caused problems in the past and that donors themselves are part of an aid-recipient country's political economy. This is good progress.

We are witnessing greater responsiveness. The Monterrey agreement to monitor donors as well as recipients is beginning to be implemented (Killick 2004). Those donor governments which have most embraced rights-based approaches, such as Sweden, are asking recipient governments to evaluate their aid programmes. In other cases, recipients are insisting on it. More donors are being more transparent about their budgets, including the costs of their own staff. These and other efforts signal real concern to promote recipient ownership. (Eyben and Ferguson 2004).

Nevertheless, a certain powerful worldview, developed during the era of European expansion, and reinforced by current global considerations, is resisting rather than embracing the possibilities for transformative change offered by paradox and unpredictability. Donors are finding it difficult even to learn that they are learning. Thus, in conclusion, I offer some practical tips for tackling these learning difficulties.

\section{Some learning tips for donors} 8.1 Recognise the paradox and improvise "Muddling through" is sometimes the best way of making progress, as DFID admits in its new Fragile States Policy Paper.

\subsection{Rethink "performance"}

Organisations make a difference not only through formal interventions related to objectives, but though the relationships and influence they have on others, the values they represent and spread, and how the worth of their intervention is judged by others (Roche and Kelly 2003; Bagic 2004). The scope of evaluations might include such matters.

\subsection{Recognise that the aid relationship has a history}

Making connections to the historical landscape of power ${ }^{14}$ from which current practice has developed not only enriches our understanding but also offers greater possibility of learning to change and of reestablishing relationships on a more honest footing.

\subsection{Spend time with people living in poverty}

This is good practice for staff from recipient as well as donor governments. Doing it together is even better. Paradoxically, as aid agencies focus more on reducing poverty reduction, practitioners are spending more time in capital cities negotiating budget support, and less time in the company of poor people. The rapidly changing realities of poor people's lives and aspirations mean that direct experience of that reality swiftly becomes dated. Making assumptions from knowledge based on experience from long ago can lead to erroneous conclusions (Irvine et al. 2004).

\subsection{Gather honest feedback}

This may not be easy, particularly in aid-dependent countries (O'Dwyer 2005). Nevertheless, it is remarkable how resistant donor governments are to even try to establish regular social audits as a routine 360 degree-type process with their different stakeholders. Such audits, when well designed, can trigger significant learning without being excessively expensive (compared for example with the resources invested in computerised management information system (MIS) programmes). That there is such strong resistance to their use indicates the challenge donors still face in admitting to their learning difficulties. 


\section{Notes}

1. Reportedly said by Karl Deutsch and quoted by Michael Cox at the Millennium Journal conference at the London School of Economics on 30 October 2004. See also Chambers' (1997) argument about how power deceives.

2. Although I draw largely on my direct experience and knowledge of the Department for International Development (DFID) and Whitehall, the argument that follows also includes reflections from interviews with staff in the Swedish International Development Agency (SIDA) and the Ministry of Foreign Affairs in Stockholm in March 2004 and feedback from a Swiss Development Cooperation workshop on accountability in Berne in October of that year. I am grateful to Itil Asmon for commenting on an earlier draft.

3. Recently I was at a meeting between a small number of civil servants from two different Departments discussing why Whitehall was not interested in learning. They unconsciously emphasised the point through their nervous comments that whatever they said should not go beyond 'these four walls'.

4. For example, Bentley and Wilsdon (2003); Courpasson and Reed (2004); Lindblom (1990); Scott (1998); Senge (1990).

5. A possibly apocryphal story I have heard in relation to the current troubled state of Nepal concerns a bilateral aid agency's security instructions to staff that should they encounter Maoist insurgents while on a project supervision visit, they should provide budgets, accounts and any other information that the guerrillas may require. My informant remarked that the power of the gun appeared to be making donors more accountable.

6. Although I am not convinced that ordinary citizens would not be amenable to the use of other accountability mechanisms where they rather than govern-

\section{References}

Bagic, A., 2004, 'Talking About Donors', in J. Gould and H.S. Marcussen (eds), 'Ethnographies of aid - exploring development texts and encounters', Occasional Paper 24, Roskilde: International Development Studies

Beck, U., 1992, The Risk Society, London: Sage

Bentley, T. and Wilsdon J. (eds), 2003, The Adaptive State, London: Demos

Biggs, S. and Smith, S., 2003, 'A paradox of learning in project cycle management and the role of organizational culture', World Development, Vol 31 No 10: 1743-58

Brock, K., Cornwall, A. and Gaventa, J., 2001, 'Power, knowledge and political spaces in the ment might be more in control. See also Roche and Kelly (2003: 10-11) on the degree to which the public in donor countries will be effectively engaged in changing the stranglehold of treasuries and audit offices, who promote accountability in their name.

7. See de Certeau 1988 for a discussion of this matter developing the Foucauldian idea of power generating its own resistance.

8. 'Managing for results is an iterative management approach. There is constant feedback to the planning and management process as results are assessed. Based on constant feedback of performance information from: audits, management reviews, performance measurement activities and evaluations, the inputs and activities can be modified and other implementation adjustments made' (Meier 2003: 24). This is a classic description of "single loop learning" by the head of the RBM unit in the Canadian International Development Agency (CIDA).

9. Edgren (2003) notes the conflict in interpretation on this point in two different SIDA-commissioned studies on donorship and ownership.

10. I am aware that participatory methods as recommended for the development of Poverty Reduction Strategies are intended to address this problem, but see Brock et al. (2001) for a discussion of the limitations of these methods in such contexts.

11. See also Carlson and Wohlgemuth (2000).

12. I deal extensively with this issue in Eyben (2003), Eyben and Ferguson (2004) and Eyben with León (2005, forthcoming).

13. See the discussion of this point with regard to DFID's experience in Brazil in Guimaraes and Larbi-Jones (2005, forthcoming).

14. I am indebted to Pfohl (2005) for this turn of phrase.

framing of poverty policy', IDS Working Paper 143, Brighton: Institute of Development Studies Carlsson, J. and Wohlgemuth, L., 2000, 'Introduction', in J. Carlsson and L. Wohlgemuth (eds), 'Learning in Development Co-operation', EGDI Study 2000: 2, Stockholm: Ministry of Foreign Affairs

Castells, M., 1997, The Power of Identity, Oxford: Blackwell

Chambers, R., 1997, Whose Reality Counts?, London: Intermediate Technology Development Group Chandler, J., 2003, 'Rhetoric without responsibility: the attraction of "ethical” foreign policy', British Journal of Politics and International Relations, Vol 5 No 3: 295-316 
Chapman, J., 2002, System Failure. Why Governments Must Learn to Think Differently, London: Demos

Clegg, S., Vierra da Cunha, J. and Pinha e Cunha, M., 2004, 'Management paradoxes: a relational view', Human Relations, Vol 55 No 5: 483-503

Common, R., 2004, 'Organisational learning in a political environment', Policy Studies, Vol 25 No 1: 35-49

Courpasson, D. and Reed, M., 2004, 'Introduction: bureaucracy in the age of enterprise', Organisation, Vol 11 No 1: 5-12

Curtis, D., 2004, "How we think they think": thought styles in the management of international aid', Public Administration and Development, Vol 24 No 5: 415-24

de Certeau, M., 1988, The Practice of Everyday Life, Berkeley: University of California Press

DFID, 2005, Why We Need to Work More Effectively in Fragile States, London: Department for International Development

Edgren, G., 2003, 'Donorship, ownership and partnership', SIDA Studies in Evaluation 03/03, Stockholm: Swedish International Development Agency

Eyben, R. with León, R., 2005, 'Whose Aid? The Case of the Bolivian Elections Project', in D. Lewis and D. Mosse (eds), Anthropology Upstream, London: Pluto Press, forthcoming

Eyben, R. and Ferguson, C., 2004, 'How Can Donors Become More Accountable to Poor People?', in L. Groves and R. Hinton (eds), Inclusive Aid, London: Earthscan

Eyben, R., 2003, 'Donors as political actors: fighting the Thirty Years War in Bolivia', IDS Working Paper 183, Brighton: Institute of Development Studies

Foucault, M., 1980, Power/Knowledge: Selected Interviews and Other Writings, New York: Pantheon Books

Geyer, R., 2003, 'Beyond the Third Way: the science of complexity and the politics of choice', British Journal of Politics and International Relations, Vol 5 No 2: 237-57

Groves, L. and Hinton, R., 2004, 'The Complexity of Inclusive Aid', in L. Groves and R. Hinton (eds), Inclusive Aid, London: Earthscan

Guimaraes, A. and Larbi-Jones, E., 2005, 'Investing in relationships: a road for organisational change in DFID Brazil', Lessons for Change 10, Brighton: Institute of Development Studies, forthcoming International Monetary Fund (IMF), 2002,
'Financing for development implementing the Monterrey Consensus', paper prepared by the staff of the World Bank and the IMF for the Spring 2002 Development Committee Meeting, 11 April 2002, www.imf.org/external/np/ pdr/FfD/2002/ imp.htm (accessed February 2005)

Irvine, R., Chambers, R. and Eyben, R., 2004, 'Learning from poor people's experience. Immersions', Lessons for Change 13, Brighton: Institute of Development Studies

Johnson, C., 2005, 'Report of a workshop on social accountability held in October 2004, unpublished paper, Berne: Swiss Agency for Development and Cooperation

Killick, T., 2004, 'Monitoring partnerships. Aidbased relationships. A note', Development Policy Review, Vol 22 No 2: 229-34

Lindblom, C., 1990, Inquiry and Change: The Troubled Attempt to Understand and Shape Society, New Haven: Yale University Press

McGee, R., 2004, 'Unpacking Policy: Actors, Knowledge and Spaces', in K. Brock, R. McGee and J. Gaventa (eds), Unpacking Policy: Actors, Knowledge and Spaces in Poverty Reduction in Uganda and Nigeria, Kampala: Fountain Publishers

Meier, W., 2003, 'Results-based management: towards a common understanding among development cooperation agencies', Discussion Paper, prepared for the Canadian International Development Agency, Performance Review Branch, for consideration by the DAC Working Party on Aid Effectiveness and Harmonisation, www.managingfordevelopmentresults.org/ (accessed 7 February 2005)

Nietzsche, F., 1873, On the Use and Abuse of History for Life, trans. I. Johnston, www.mala.bc.ca/ johnstoi/Nietzsche/history.htm (accessed 1 February 2005)

O'Dwyer, B., 2005, 'The construction of social account: case study in an overseas aid agency', Accounting, Organisations and Society, Vol 30: 279-96

Ostrom, E., Clark, G., Shivkuman, S. and Anderson, K., 2002, 'Aid, incentives and sustainability: an institutional analysis of development cooperation', SIDA Studies in Evaluation 02/01:1, Stockholm: Swedish International Development Cooperation Agency

Overseas Development Institute (ODI), n.d., 'Aid effectiveness and good donorship', Research 
Stream No. 1: Aid Policy and Donor Practice, Centre for Aid and Public Expenditure (accessed 24 January 2005)

Pasteur, K., 2004, 'Learning for development. A literature review', Lessons for Change 6, Brighton: Institute of Development Studies

Pentland, B., 2000, 'Will auditors take over the world? Program, technique and the verification of everything', Accounting, Organizations and Society, Vol 25: 307-12

Pfohl, S., 2005, 'Culture, power, and history: an introduction', Critical Sociology, Vol 30 No 2: 191-205

Power, M., 1996, 'Making things auditable', Accounting, Organizations and Society, Vol 22: 123-46

Roche, C. and Kelly, L., 2003, 'Evaluating the performance of development agencies', paper prepared for the Fifth Biennial World Bank Conference on Evaluation and Development, 'Evaluating Development Effectiveness: Challenges and the Way Forward', Washington, DC, 15-16 July 2003
Saltmarshe, D., Ireland, M. and McGregor, J.A., 2003, 'The performance framework: a systems approach to understanding performance management', Public Administration and Development, Vol 23: 445-56

Scott, J., 1998, Seeing Like a State, New Haven: Yale University Press

Senge, P., 1990, The Fifth Discipline: The Art and Practice of the Learning Organisation, New York: Doubleday

Strathern, M., 2000, 'Accountability and Ethnography', in M. Strathern (ed.), Audit Cultures, London: Routledge: 279-304

United Nations, 2005, Investing in Development. UN Millennium Development Project Report, www.unmillenniumproject.org/ (accessed February 2005)

Vince, R., 2001, 'Power and emotion in organizational learning', Human Relations, Vol 54 No 10: 1325-51 